\title{
REGENERATION OF POST-TRAUMATIC SEGMENTAL BONE DEFECTS IN DISTAL FEMUR BY MASQUELET TECHNIQUE- AN OBSERVATIONAL STUDY
}

\author{
Ramesh Balusamy1, Vijayakumar Palanimalai²
}

${ }_{1}^{1}$ Assistant Professor, Department of Orthopaedics, KAP Viswanatham Government Medical College, Tiruchirapalli.

${ }^{2}$ Senior Assistant Professor, Department of Orthopaedics, KAP Viswanatham Government Medical College, Tiruchirapalli.

\begin{abstract}
BACKGROUND
ABSTRACT

Masquelet technique is a two-staged procedure in the treatment of bone loss. In stage one, an antibiotic-impregnated cement spacer is placed in the bone defects after thorough debridement. This cement spacer induces a foreign body reaction around the bone defect which creates a fibrous biological membrane. Stage two consists of placing bone grafts within the membrane. The biological membrane helps in bone graft integration and bone formation.

The aim of the study was to study regeneration of bone in the Post-traumatic bone defect area of distal femur by Masquelet technique.
\end{abstract}

\section{MATERIALS AND METHODS}

The present observational study was carried out in MGM Government Hospital/KAPV Government Medical College from 2010 to 2016. The study consisted of 40 adult patients with distal femur bone loss, satisfying the inclusion criteria.

\section{RESULTS}

We achieved healing in all our patients. Average time of radiographic bone consolidation was 10.5 months.

\section{CONCLUSION}

From our study, we safely conclude that Masquelet technique is an alternate method in treatment of Post-traumatic bone loss in distal femur with acceptable results.

\section{KEYWORDS}

Bone Loss, Distal Femur, Masquelet Technique, Bone Cement Spacer, Biomembrane.

HOW TO CITE THIS ARTICLE: Balusamy R, Palanimalai V. Regeneration of Post-traumatic segmental bone defects in distal femur by Masquelet technique- An observational study. J. Evolution Med. Dent. Sci. 2018;7(02):207-210, DOI: 10.14260/jemds/2018/46

\section{BACKGROUND}

Post-traumatic segmental bone loss in femur is a difficult task to manage and is associated with significant longterm morbidity.(1) Historically, it was managed with massive cancellous bone graft, $(1,2)$ Ilizarov technique, Vascularised fibular graft and limb shortening. All these techniques are associated with variable results like uncontrollable bone resorption in traditional massive bone grafting(3) and so failure in bone regeneration. To overcome this, Masquelet described a technique of inducing biomembrane in the bone defects by placing antibiotic-integrated bone cement as a spacer in the bone defects. After around four weeks, the antibiotic bone cement-induced foreign body reaction forms a biomembrane at the bone defect site which reduces the rate of bone graft resorption.(4,5) The biomembrane-induced growth factors BMP2, VEGF, TGF, Vwf and IL-6 helps in better integration of bone graft and bone regeneration.(6) This study describes the clinical outcome in the series of patients with distal femur bone loss treated by Masquelet technique at our institution.

'Financial or Other Competing Interest': None.

Submission 14-11-2017, Peer Review 21-12-2017,

Acceptance 27-12-2017, Published 08-01-2018.

Corresponding Author:

Ramesh Balusamy,

Flat No 302, C-95, SS Residency,

$10 A$ West Cross, Thillai Nagar,

Trichy-18, Tamilnadu.

E-mail: rameshcallsyou@gmail.com

DOI: $10.14260 /$ jemds $/ 2018 / 46$

\section{Aim of the Study}

To study regeneration of bone in the post-traumatic bone defect area of distal femur by Masquelet technique.

\section{MATERIALS AND METHODS}

The present study is an observational study. The period of our study was 2010 to 2016. All cases admitted in the trauma ward at our institution with following inclusion and exclusion criteria were included in the study.

\section{Inclusion Criteria}

Post-traumatic bone losses of size $3 \mathrm{~cm}$ and above in distal femur with open injury.

\section{Exclusion Criteria}

1. Post-traumatic Bone loss with severe contamination.

2. Wound with extensive soft tissue loss (Gustilo-Anderson Type IIIB).

Bone cement used was Polymethylmethacrylate (PMMA), and Vancomycin was the antibiotic used for cement impregnation. Distal femur locking plate was used in all our patients for primary stabilisation. Cancellous bone graft was harvested from opposite side iliac crest and ipsilateral side distal femoral canal.

Studies shows that autograft from femoral canal has more level of growth factors than that of iliac crest.(7) Fibular strut graft was harvested from same side of the leg and used in cases where bone loss was more than $6 \mathrm{~cm}$ and above.

The length of bone defect, duration of cementation, duration of union after bone grafting, whether fibular strut 
graft used and the complications encountered were recorded in our study.

\section{Surgical Technique}

Preoperative templating of injured bone was done initially to find out length of bone loss, rotation and alignment of injured limb. Thorough wound debridement was done with copious amount of normal saline. The wound was extended proximally and distally and dissected up to the area of bone loss. The debris and nonviable tissues were removed. Bone ends freshened and fixed with distal femur locking compression plating after maintaining length, alignment and rotation of limb (Figure 1). The bone defect was then measured and spacer of measured length was prepared using bone cement and antibiotic. The cement spacer was allowed to set and then placed in the bone defect space once it becomes hard. (Figure 2). The second stage was done after 4 to 10 weeks of first stage depending up on wound condition. The cement spacer placed defect site was approached directly through an incision over the original wound and by same plane incision of subcuticular tissues. The biomembrane encapsulating the spacer was identified and a careful incision was done on it to retrieve the bone cement spacer. After removal of spacer the bone ends were freshened so as to stimulate bone growth, the biomembrane capsule was irrigated to remove any residual debris and the harvested bone grafts from iliac crest and cancellous autograft from femoral canal were placed in the fibrous capsule biomembrane pocket/defect (figure 3). In patients with bone defect more than $6 \mathrm{~cm}$ fibular strut graft was used along with cancellous bone graft (Figure 4). The fibrous membrane was closed as a separate layer using absorbable suture material and wound closed in layers.

\section{RESULTS}

Total of 40 patients with segmental bone loss of distal femur were included in our study which includes 32 male and 8 females with mean age of 32.6 (26-42). The length of bone defect ranged from $3 \mathrm{~cm}$ to $9 \mathrm{~cm}$ and the mean bone loss defect was $6.5 \mathrm{~cm}$. The mean interval between first stage and second stage surgeries was 41.5 days (35 to 50 days). Radiographic consolidation of bone graft over the defect was noted in all our patients. (Figure 5). Mean bone consolidation period was 10.5 months (7 to 16 months). No major complications other than minor skin infections were noted in our study. Fibular strut graft along with cancellous bone graft was used in 14 cases in our study.

\begin{tabular}{|c|c|c|}
\hline Sl. No. & Particulars & No. \\
\hline 1 & Total cases & 40 \\
\hline 2. & Fibular strut graft used & 16 \\
\hline 1 & Mean Age & 32.6 Years \\
\hline 2 & Mean Bone loss & $6.5 \mathrm{~cm}$ \\
\hline 3 & Mean Interval between two surgeries & 41.5 Days \\
\hline 4. & Mean Bone Consolidation Period & 10.5 \\
& Table 1. Summary of Statistics \\
\hline \multicolumn{3}{|c|}{} \\
\hline
\end{tabular}

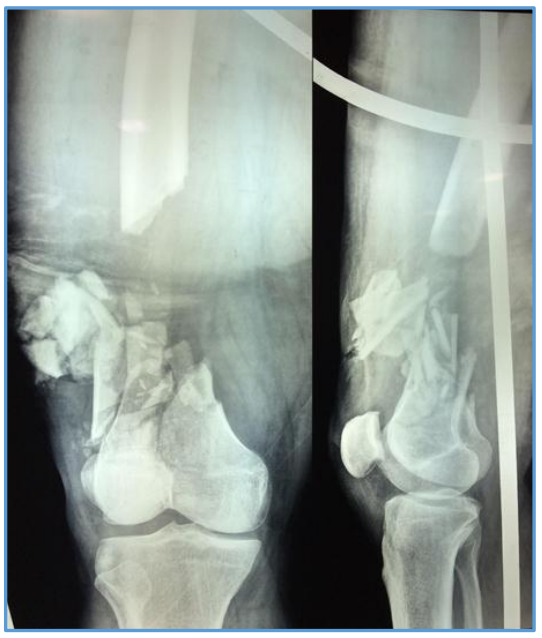

Figure 1. X-ray showing Bone Loss

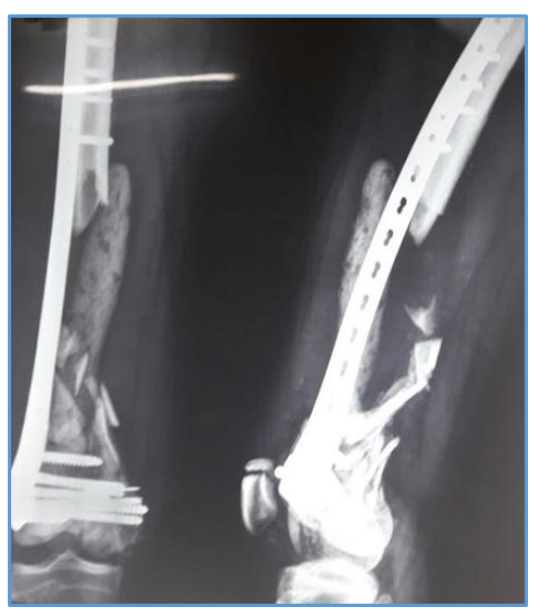

Figure 2. X-ray showing Bone Stabilisation with Cement Spacer in situ, Stage one Procedure

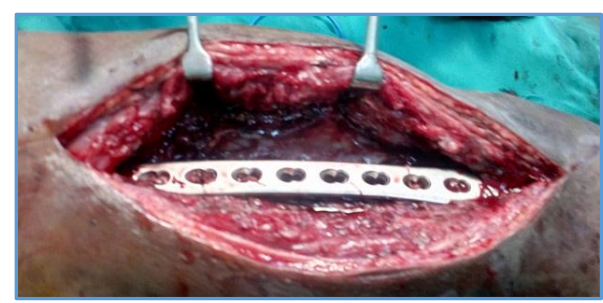

Figure 3. Intraoperative Picture showing Biomembrane

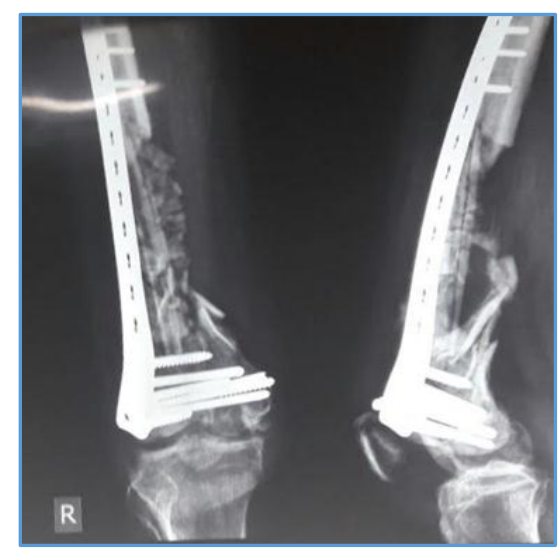

Figure 4. Fibular Strut Graft and Cancellous Bone Graft after Retrieval of Bone Spacer 


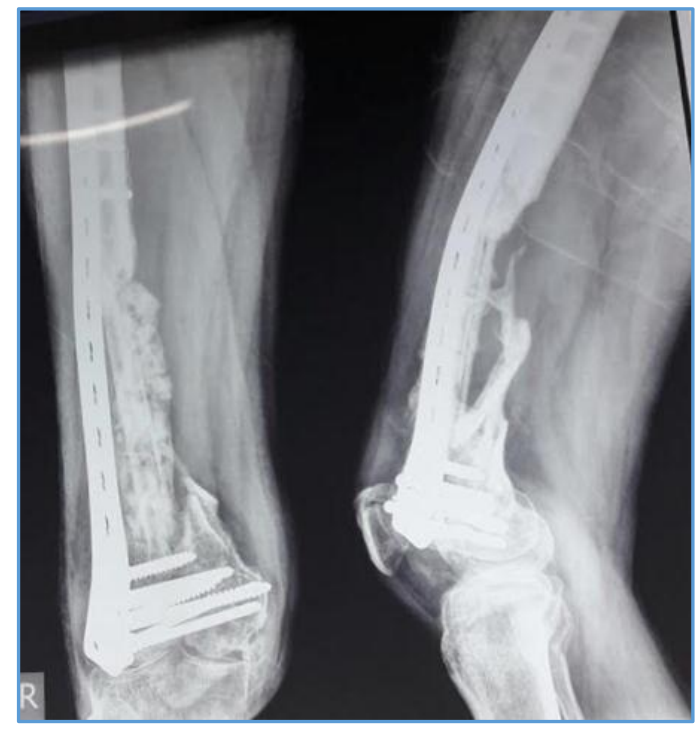

Figure 5. Six months Followup X-ray showing Graft Integration

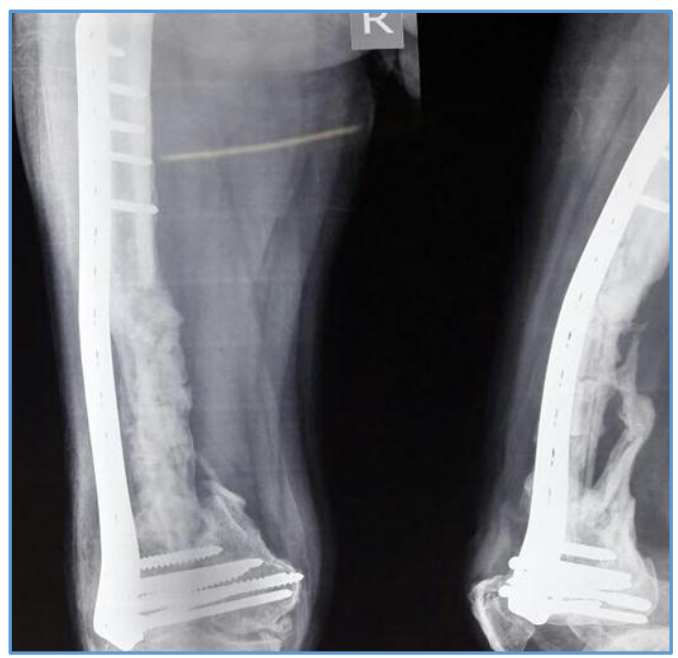

Figure 6. Eleven Months Followup X-ray showing Bone Consolidation

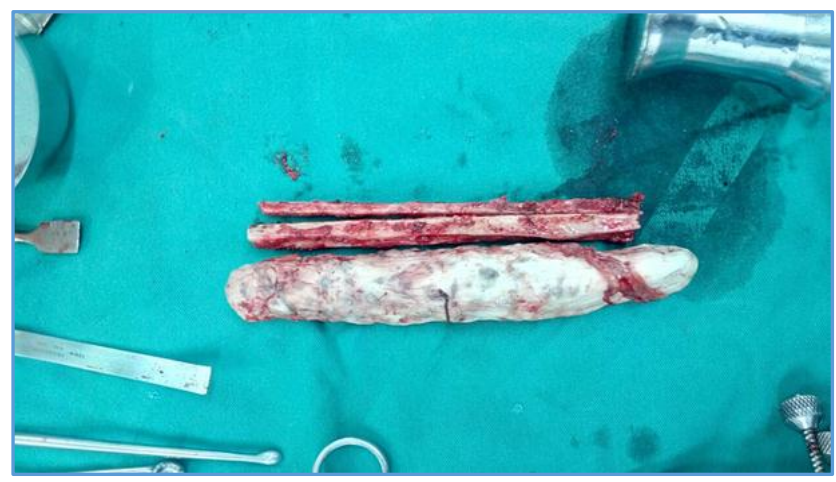

Figure 7. Retrieved Bone Cement Spacer and Fibular Strut Graft

\section{DISCUSSION}

Regeneration in the segmental bone loss is a challenge for orthopaedic surgeons. Historically, these defects were treated with massive bone grafting of the defect which often fails due to graft resorption. Earlier in this century, Alain Masquelet(7) described and published a surgical technique of a staged procedure of inducing a biologically active membrane at the defect site. He found that this biomembrane helps in graft containment and integration. The biomembrane formed at the defect site is due to body's foreign body reaction to the antibiotic-impregnated cement spacer. Second stage of bone grafting is done after an interval of 5 weeks to favour formation and maturation of biomembrane formation in the defect that is suitable for grafting and soft tissue healing. ${ }^{(8)}$

Vancomycin-impregnated cement spacers are used for local administration of antibiotic to the soft tissue bed. Placing such a spacer not only provides structural support but also maintains void space in the defect by inhibiting fibrous ingrowth(9) for later bone grafting and foreign body-induced biomembrane formation. C.Y-L.Woon et al found that the thickness of this biomembrane can be 0.5 to $1 \mathrm{~mm}$ thick which is hypervascular and impermeable.(10,11) Pelissier et al(11) in their paper reported that this membrane secretes growth factors and osteoinductive factors which are responsible for stimulation of bone growth and graft integration. Chris Christou(11) described that the immunohistochemical marker expression studies show BMP2 on the surface of membrane and TGF $b$ in both surfaces of membrane and deeper tissues, VEGF in the membrane and blood vessels around the membrane. ${ }^{(11,12)}$ These boneinducing agents helps in consolidation of bone grafts placed inside the membrane which was studied by Aho and his colleagues.(13) They also found that one-month-old membrane has higher osteogenesis potential compared with two-monthold membrane and concluded that optimal time for performing second stage surgery may be within a month after implantation of foreign material.(13,14)

Regarding primary stabilisation of fracture after debridement we used distal femur locking plate in all our cases. Biau et al described a case of distal femur bone loss stabilised with intramedullary nail and antibiotic spacer followed by secondary grafting and eventual healing.(15) A series of 12 cases with tibial bone loss stabilised with intramedullary nail and secondary bone grafting was published by Apard et al. He reported an average healing time of 4 months.(16) R. Sivakumar et al reported a case series of distal femur bone loss stabilised with distal femur locking plate and grafting and found that this technique is relatively less cumbersome than Ilizarov which is considered to be an alternative mode treatment for these type of fractures.(17)

Though there was no implant failure in our study, plate bending was noted in 5 patients with bone loss more than 8 $\mathrm{cm}$. There continues a debate regarding the ideal implant for primary fixation in this technique as too rigid construct may be stress shielding near the plate thereby reducing integration of bone graft near the implant as reported by Tak Man Wong et al.(18)

\section{CONCLUSION}

The two-staged technique of bone regeneration seems to be a notable alternative in the management of segmental bone loss after trauma in distal femur. The foreign body-induced biomembrane provides a void for cancellous bone grafting and helps in bone formation and consolidation. Younger age patients with better healing potential, patients without any associated morbidity, wound with no contamination and possible coverage are possible reasons for better outcome in our study. Wide application of study for longer duration in all 
age groups, with all type of wounds and with variable implant of choice for primary stabilisation of bone will help to evaluate the effectiveness of this technique and the implant of choice for this procedure in future.

\section{REFERENCES}

[1] Watson JT, Anders M, Moed BR. Management strategies for bone loss in tibial shaft fractures. Clin Orthop Relat Res 1995;315:138-52.

[2] Hertel R, Gerber A, Schlegel U, et al. Cancellous bone graft for skeletal reconstruction. Muscular versus periosteal bed-preliminary report. Injury 1994;25(Suppl 1):A59-70.

[3] Masquelet AC, Begue T. The concept of induced membrane for reconstruction of long bone defects. Orthop Clin North Am 2010;41(1):27-37.

[4] Masquelet AC, Fitoussi F, Begue T, et al. Reconstruction of the long bones by the induced membrane and spongy autograft. Ann Chir Plast Esthet 2000;45(3):346-53.

[5] Knothe Tate ML, Chang H, Moore SR, et al. Surgical membranes as directional delivery devices to generate tissue: testing in an ovine critical sized defect model. PLoS One 2011;6(12):e28702.

[6] Geiger F, Lorenz H, Xu W, et al. VEGF producing bone marrow stromal cells (BMSC) enhance vascularization and resorption of a natural coral bone substitutes. Bone 2007;41(4):516-22.

[7] Schmidmaier G, Herrmann S, Green J, et al. Quantitative assessment of growth factors in reaming aspirate, iliac crest and platelet preparation. Bone 2006;39(5):1156-63.

[8] Masquelet AC. Muscle reconstruction in reconstructive surgery: soft tissue repair and long bone reconstruction. Langenbeck's Arch Surg 2003;388(5):344-6.

[9] McCall TA, Brokaw DS, Jelen BA, et al. Treatment of large segmental bone defects with reamer-irrigatoraspirator bone graft: technique and case series. Orthop Clin North Am 2010;41(1):63-73.
[10] Viateau V, Guillemin G, Calando Y, et al. Induction of a barrier membrane to facilitate reconstruction of massive segmental diaphyseal bone defects: an ovine model. Vet Surg 2006;35(5):445-52.

[11] Woon CY, Chong KW, Wong MK. Induced membranesa staged technique of bone grafting for segmental bone loss: a report of two cases and a literature review. J Bone Joint Surg Am 2010;92(1):196-201.

[12] Pelissier P, Masquelet AC, Bareille R, et al. Induced membranes secrete growth factors including vascular and osteoinductive factors and could stimulate bone regeneration. J Orthop Res 2004;22(1):73-9.

[13] Christou C, Oliver RA, Yu Y, et al. The Masquelet technique for membrane induction and healing of ovine critical sized segmental defects. PLoS One 2014;9(12):e114122.

[14] Aho OM, Lehenkari P, Ristiniemi J, et al. The mechanism of action of induced membranes in bone repair. J Bone Joint Surg Am 2013;95(7):597-604.

[15] Neufeld G, Cohen T, Gengrinovitch S, et al. Vascular endothelial growth factor VEGF and its receptors. FASEB J 1999;13(1):9-22.

[16] Biau DJ, Pannier S, Masquelet AC, et al. Case report: reconstruction of a 16-cm diaphyseal defect after Ewing's resection in a child. Clin Orthop Relat Res 2009;467(2):572-7.

[17] Apard T, Bigorre N, Cronier P, et al. Two stage reconstruction of post traumatic segmental tibia bone loss with nailing. Orthop Traumatol Surg Res 2010;96(5):549-53.

[18] Sivakumar R, Mohideen MG, Chidambaram M, et al. Management of large bone defects in Diaphyseal fractures by induced membrane formation by Masquelet's technique. J Orthop Case Rep 2016;6(3):59-62. 